\title{
Predictors of smoking cessation in a cohort of adult smokers followed for five years
}

Department of Psychiatry, University of Medicine and Dentistry of New Jersey, Newark, New Jersey, USA N Hymowitz

Department of Cancer Control and Epidemiology, Roswell Park Cancer Institute, Buffalo, New York K M Cummings A Hyland

Cancer Control Science Program, National Cancer Institute, Rockville, Maryland

W R Lynn

Office on Smoking and Health, Centers for Disease Control and Prevention, Atlanta, Georgia

T F Pechacek

Center for Medical Statistics, Research Triangle Institute, Research Triangle Park, North Carolina T D Hartwell

Correspondence to: Dr K Michael Cummings, Department of Cancer Control and Epidemiology, Roswell Park Cancer Institute, Elm and Carlon Streets, Buffalo, New York 14263, USA; email: mcummings@sc3102.med. mcummings

Norman Hymowitz, K Michael Cummings, Andrew Hyland, William R Lynn, Terry F Pechacek, Tyler D Hartwell

Abstract

Objective-To identify variables predictive of smoking cessation in a cohort of cigarette smokers followed for five years. Design-Data analysed in this paper come from a cohort tracking telephone survey of 13415 cigarette smokers aged 25-64 years from 20 American and two Canadian communities who were interviewed in 1988 and re-interviewed in 1993 as part of the National Cancer Institute's Community Intervention Trial for Smoking Cessation. Predictors of smoking cessation evaluated in this study included measures of past and current smoking behaviour, past quit attempts, stated desire to quit smoking, and demographic characteristics.

Outcome measures-Smoking cessation was based on self report. A "quitter" was defined as a cohort member who, at the final annual contact in 1993, reported not smoking any cigarettes for the preceding six months or longer. Any smoker who reported having made a serious quit attempt between 1988 and 1993 was asked to indicate reasons that contributed to their decision to try to stop smoking.

Results-67\% of smokers reported making at least one serious attempt to stop smoking between 1988 and 1993 and, of these, $33 \%$ were classified as having quit smoking in 1993. The most common reasons given for quitting smoking were concern over health $(91 \%)$, expense $(60 \%)$, concern about exposing others to secondhand smoke $(56 \%)$, and wanting to set a good example for others (55\%). Statistically significant predictors of smoking cessation included male gender, older age, higher income, less frequent alcohol intake, lower levels of daily cigarette consumption, longer time to first cigarette in the morning, the use of premium cigarettes, initiation of smoking after age 20 , history of past quit attempts, a strong desire to stop smoking, and the absence of other smokers in the household. Predictor variations with the largest relative risks for smoking cessation were those associated with nicotine dependence such as amount smoked daily and time to first cigarette in the morning.

Conclusions-Despite the fact that most smokers expressed a strong desire to stop smoking in 1988, the majority, especially the most dependent heavy smokers $(>25$ cigarettes/day), struggled unsuccessfully to achieve this goal.

(Tobacio Control 199-;6 (suppl 2):S5i-S62)

Keywords: smoking cessation predictors

\section{Introduction}

Cigarettes cause more illness and death in the United States than anything else. ${ }^{1}$ It is well accepted that nicotine in cigarettes contributes to the struggle that many smokers experience in stopping smoking. ${ }^{2-6}$ Despite attempts by the cigarette industry to frame the debate on smoking as the right of each person to choose to smoke or not smoke, the facts speak differently. Surveys show that $70 \%$ of smokers wish they could quit ${ }^{7}$; for every smoker who does quit, nine try and fail ${ }^{8}$; and studies have repeatedly shown that the more dependent a person is on nicotine, the more difficulty they have in quitting. ${ }^{912}$ For example, in a recent study examining predictors of quitting in a cohort of California smokers followed for two years, Farkas $e t$ al found that measures of nicotine dependence were stronger predictors of quitting than measures of motivation and readiness to stop smoking. ${ }^{13}$

Recent studies have identified a number of variables associated with success in quitting smoking. ${ }^{914}$ Among these are: smoking fewer cigarettes daily, past quit attempts, higher socioeconomic level, and older age. ${ }^{9}$ Female gender, African American race, and recent use of alcohol, on the other hand, have been associated with a lower likelihood of quitting. ${ }^{914-16}$ The COMMIT study, which tracked the smoking habits of a cohort of smokers over a five-year period, provides a unique opportunity to investigate individual-level predictors of smoking cessation. The following questions were used to guide analyses of data.

- What percentage of smokers express a desire to stop smoking? How many of these actually attempt to quit, and of these how many succeed?

- What are the most common reasons smokers give for quitting smoking? Do the reasons given for quitting smoking differ between those who do or do not succeed in quitting?

- What characteristics of smokers are predictive of success in stopping smoking?

The findings from this study should contribute to our understanding of factors underlying smoking cessation and thus aid in the development of public health interventions to assist smokers in stopping smoking. 
Methods

COMMIT STUDY

The data analysed in this paper come from a longitudinal study involving 13415 cigarette smokers from 20 American and two Canadian communities who were interviewed in 1988 and re-interviewed in 1993 as part of the National Cancer Institute's Community Intervention Trial for Smoking Cessation (COMMIT) study. The design and primary outcomes have been described previously. ${ }^{17}$

DATA COLLECTION

From January to May 1988, a telephone survey was conducted to identify cohorts of approximately 915 current cigarette smokers aged 25-64 years in each of the 22 study communities (see reference 17 for a list of the 22 COMMIT study communities). The survey was conducted centrally using a modified, random-digit dialling technique and community-specific geographic screening to identify households within the targeted areas. Most of the questions which made up the survey were taken from earlier national surveys of smoking behaviour such as the 1986 Adult Use of Tobacco Survey and the 1987 National Health Interview Survey. ${ }^{20} 21$ The survey was implemented in two stages. The first stage involved identifying representative samples averaging 5400 households within each community and gathering information on the age, gender, and smoking habits of all adults within selected households. (This stage is referred to as the rostering stage.) In the second stage, a sample of current smokers aged 25-64 years was selected for an extended interview which included questions about current and past smoking habits, brand and type of cigarette usually smoked, interest in quitting smoking, alcohol consumption, the presence of other smokers in the household, and sociodemographic characteristics. For the purposes of this study, current smokers were defined as those who, in 1988, reported having smoked at least 100 cigarettes in their lifetime and who reported smoking at the time of interview.

The mean response rate for the household rostering portion of the survey was $83.7 \%$. Of the eligible smokers identified for the household rostering, $91.5 \%$ completed the extended interview. The initial cohort identification survey gathered data on a total of 20272 current smokers aged 25-64 years who were then followed prospectively until 1993 .

Between 1988 and 1992, cohort participants were contacted once per year either by telephone or mail to assess their current smoking status and residency. To ensure that the cohorts remained as representative as possible of their communities, telephone contact with cohort members was kept to a minimum. Thus, although it may have been valuable to question cohort members about their smoking habits during the interim years, such questions were not permitted. However, between January and May 1993 cohort members were asked to respond to a 20-minute telephone interview which included questions about current smok- ing status, efforts made to stop smoking since 1988 , and reasons given for attempting to stop smoking.

Overall, $66.2 \%$ of cohort members ( $\mathrm{n}=$ 13415 ) provided information on their smoking status at the final contact in 1993. Most of the cohort members who were classified as non-responders were those who could not be located $(29.9 \%, n=6052)$, were deceased $(2.4 \%, \mathrm{n}=492)$, or refused to participate in the follow-up survey $(1.5 \%, \mathrm{n}=$ 313). Compared with responders to the 1993 follow-up survey, non-responders tended to be younger, single, and had fewer years of formal education.

\section{OUTCOME MEASURES}

Smoking cessation was based on self report. A "quitter" was defined as a cohort member who, at the final annual contact in 1993, reported not smoking any cigarettes for the preceding six months or longer. Cohort participants who had quit smoking and those who were still smoking but who reported having made a serious attempt to stop smoking between 1988 and 1993 were asked to indicate whether any of the following reasons were important to them when they last tried to stop smoking: the expense of smoking; concern for current or future health; concern about the effects of passive smoking on others; pressure from family members, friends, and co-workers; restrictions on smoking at work; advice from a health professional; concern about bad breath, bad taste, smell from cigarette smoke; the desire to set a good example for children; and the death of a friend or relative. For each reason, respondents answered "yes" or "no". Thus, it was possible for respondents to mention more than one reason for attempting to stop smoking.

\section{ANALYSIS METHODS}

Estimates of the percentage of smokers who attempted to stop smoking between 1988 and 1993 , reasons for attempting to stop smoking, and the percentage who were successful in quitting were computed for all cohort members combined and separately for each of the 22 communities in the study. However, only the combined data are presented here, as the focus is on individual-level predictors of smoking cessation. The effect of the COMMIT intervention on the quit rates among cohort members has been described elsewhere. ${ }^{18}$ Briefly, the effect of the COMMIT intervention on the quit rate of cohort members was small (an overall average increased quit rate of $1.8 \%$ ), although statistically significant with a probability value of less than 0.05 . To take account of this effect, the relationship between individual-level predictors of smoking cessation are adjusted for the effects of the COMMIT intervention.

Logistic regression analysis was used to assess the association between smoker characteristics measured in 1988 and smoking cessation measured in 1993. Smoker characteristics evaluated in relation to smoking cessation included:

- Age (25-34, 35-44, 45-54, 55-64 years) 

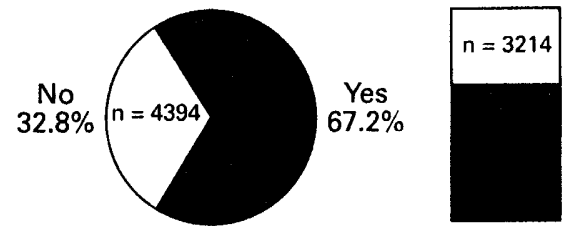

Quitter $35.6 \%$

A

B

Figure 1 (A) Reported quit attempts and (B) smoking cessation among those who made a scrious attempt to quit in a cohort of 13415 smokers follorivd between 1988 and 1993.

- Gender

- Race/ethnicity (white, black, Hispanic, Asian, American Indian, Canadian, other)

- Average annual household income (<US\$10 000, \$10 000-\$25 000, \$25001$\$ 40000,>\$ 40000$ )

- Time in formal education $(<12,12,13-15$, $>15$ years)

- Frequency of alcohol consumption (daily, 3-4 times/week, 1-2 times/week, 1-3 times/ month, $<1$ time/month)

- Cigarettes smoked daily $(<5,5-14,15-24$, >25)

- Time to first cigarette in the morning $(<10$, $10-30,31-60,>60$ minutes)

- Age began smoking ( $<16,16-19,>19$ years)

- Usual type of cigarette consumed (premium, discount, or generic brand)

- Use of non-cigarette tobacco products (none vs pipe tobacco, cigars, chew or snuff tobaccos)

- History of past quit attempts (none, one attempt, more than one attempt)

- Desire to stop smoking (none, a little, somewhat, a lot)

- Presence of another smoker in the household.

\section{Results}

QUIT ATTEMPTS AND QUIT RATE

As figure 1 shows, $67.2 \%$ of smokers reported having made at least one serious attempt to stop smoking between 1988 and 1993, and of these $32.8 \%$ were classified as quitters in 1993. In 1988, when asked the question: "How much do you want to quit smoking?", $67.6 \%$ of smokers answered either "somewhat" or "a lot". Among these individuals, $24.6 \%$ were classified as quitters in 1993.

REASONS FOR QUITTING

Table 1 shows the reasons given for attempting to quit smoking among cohort members who had quit smoking and those who were still smoking but who reported having made at least one attempt to stop smoking between 1988 and 1993. The most common reasons given for quitting smoking were concern over health $(91 \%)$, expense $(60 \%)$, concern about exposing others to secondhand smoke (56\%), and wanting to set a good example for others $(55 \%)$. The rank ordering of different reasons given for stopping smoking was similar between those who quit smoking and those who continued to smoke. However, with the exception of concern over health, endorsed by $90 \%$ of continuing smokers as well as quitters, those who continued to smoke were significantly more likely to endorse additional reasons for quitting compared with those who succeeded in stopping smoking.

\section{PREDICTORS OF QUTTTING}

Table 2 shows the results of the logistic regression analysis relating smoker characteristics measured in 1988 and smoking cessation measured in 1993. Significant predictors of smoking cessation included male gender, older age, higher income, less frequent alcohol intake, lower levels of daily cigarette consumptions, longer time to first cigarette in the morning, the use of premium cigarettes, initiation of smoking after age 20 , more than one previous quit attempt, a strong desire to stop smoking, and the absence of other smokers in the household.

Of the various smoker characteristics evaluated, indicators of nicotine dependence, such as amount smoked daily and time to first cigarette of the day, were most strongly correlated with smoking cessation. Figure 2 shows the relationship between the amount smoked daily in 1988 and the likelihood of being classified as a quitter in 1993. A similar relationship is seen when other measures of nicotine dependence are substituted for amount smoked daily. In a simple linear regression analysis where all of the predictor variables measured in this study are included in the model (data not presented), measures of nicotine dependence account for 10 times the variance in smoking cessation than indicators of motivation to stop smoking, such as past quit attempts and expressed desire to quit.

\section{Discussion}

The data come from one of the largest community intervention studies ever undertaken to track the smoking habits of a non-clinic based group of smokers over an

Table 1 Reasons for quitting among those who made a serious quit attempt between 1988 and 1993

\begin{tabular}{|c|c|c|c|}
\hline Reason & $\begin{array}{l}\text { Continuing smokers } \\
(n=5807)(\%)\end{array}$ & $\begin{array}{l}\text { Successful quitters } \\
(n=3214)(\%)\end{array}$ & $\begin{array}{l}\text { Total } \\
(n=9021)(\%)\end{array}$ \\
\hline 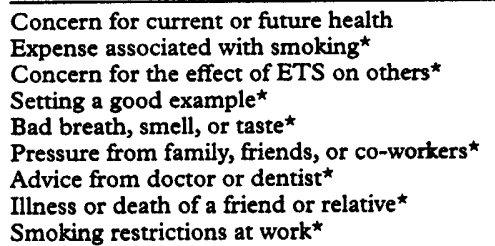 & $\begin{array}{l}90.2 \\
64.4 \\
57.4 \\
56.4 \\
49.5 \\
46.7 \\
44.0 \\
22.3 \\
22.2\end{array}$ & $\begin{array}{l}90.2 \\
52.8 \\
52.2 \\
52.4 \\
42.8 \\
37.3 \\
33.7 \\
17.8 \\
14.4\end{array}$ & $\begin{array}{l}90.2 \\
60.7 \\
55.8 \\
55.1 \\
47.3 \\
43.7 \\
40.7 \\
20.9 \\
19.7\end{array}$ \\
\hline
\end{tabular}

$\star \mathrm{P}<0.05$ for $\chi^{2}$ test of independence.

ETS $=$ environmental tobacco smoke. 
extended period of time. The results of this study are consistent with the larger body of clinic-based research on smoking cessation, which shows that success in stopping smoking is determined by the interplay of multiple factors, including combinations of psychological, physiological, and social processes. ${ }^{7} 132223$ i4

With few exceptions, the variables found to influence smoking cessation among smokers tracked as part of the COMMIT study are the same ones that have been found to be associated with cessation in clinical studies. ${ }^{9+1-16}$ For example, men were somewhat more successful than women at stopping smoking, and older smokers were more successful than younger ones. Race/ethnicity and education did not emerge as significant predictors when the data were subjected to multivariate analysis, although annual household income was positively associated with quitting. Frequency of alcohol consumption and use of generic cigarettes were inversely related to stopping smoking. Our findings reinforce the predominant view held by medical experts today, which is that maintenance of smoking behaviour in adults is strongly controlled by addiction to nicotine..$^{2-6} \mathrm{By}$ far, the most robust predictors of smoking cessation among cohort participants were measures thought to be indicative of strength

Table 2 Results of logistic regression analysis relating smoker characteristics measured in 1988 and smoking cessation measured in $1993^{*}(n=13415)$

\begin{tabular}{|c|c|c|c|c|}
\hline Characteristic & Sample size & Per cent quit & Relative risk & $95 \% C I$ \\
\hline \multicolumn{5}{|l|}{ Sex } \\
\hline Male & 6599 & 24.0 & 1.00 & Referent \\
\hline Female & 6816 & 23.9 & 0.85 & $0.78-0.94$ \\
\hline \multicolumn{5}{|l|}{ Age (years) } \\
\hline $25-34$ & 4249 & 22.8 & 1.00 & Referent \\
\hline $35-44$ & 4249 & 22.0 & 0.99 & $0.88-1.11$ \\
\hline $45-54$ & 2817 & 24.6 & 1.21 & $1.06-1.37$ \\
\hline $55-64$ & 2100 & 29.3 & 1.57 & $1.37-1.81$ \\
\hline \multicolumn{5}{|l|}{ Race } \\
\hline White & 10072 & 23.3 & 1.00 & Referent \\
\hline Black & 882 & 27.7 & 0.98 & $0.82-1.17$ \\
\hline Hispanic & 697 & 30.0 & 1.05 & $0.87-1.28$ \\
\hline Canadian & 1449 & 23.1 & 0.96 & $0.81-1.13$ \\
\hline Asian & 138 & 28.3 & 0.90 & $0.59-1.37$ \\
\hline American Indian & 117 & 20.5 & 0.89 & $0.55-1.45$ \\
\hline Other & 42 & 33.3 & 1.49 & $0.73-3.02$ \\
\hline \multicolumn{5}{|c|}{ Annual household income (US\$) } \\
\hline$<10000$ & 1139 & 20.3 & 1.00 & Referent \\
\hline $10000-25000$ & 3750 & 22.2 & 1.15 & $0.96-1.38$ \\
\hline $25001-40000$ & 4087 & 24.1 & 1.34 & $1.12-1.61$ \\
\hline$>40000$ & 3456 & 26.0 & 1.47 & $1.22-1.77$ \\
\hline \multicolumn{5}{|l|}{ Education (years) } \\
\hline$<12$ & 2528 & 22.4 & 1.00 & Referent \\
\hline 12 & 3237 & 23.8 & 1.03 & $0.89-1.19$ \\
\hline 13-15 & 5367 & 23.5 & 1.00 & $0.87-1.15$ \\
\hline$\geqslant 16$ & 2257 & 26.9 & 1.04 & $0.89-1.23$ \\
\hline \multicolumn{5}{|c|}{ Frequency of alcohol consumption } \\
\hline Daily & 1572 & 20.9 & 1.00 & Referent \\
\hline 3-4 times/week & 1286 & 21.0 & 0.98 & $0.80-1.19$ \\
\hline 1-2 times/week & 3064 & 23.4 & 1.09 & $0.93-1.29$ \\
\hline $1-3$ times/month & 2299 & 24.8 & 1.24 & $1.04-1.47$ \\
\hline$<1 /$ month or never & 5100 & 25.6 & 1.35 & $1.16-1.57$ \\
\hline \multicolumn{5}{|c|}{ Cigarettes smoked daily in 1988} \\
\hline$\geqslant 25$ & 5566 & 18.7 & 1.00 & Referent \\
\hline $15-24$ & 4783 & 22.7 & 1.15 & $1.03-1.28$ \\
\hline $5-14$ & 2356 & 32.4 & 1.59 & $1.38-1.83$ \\
\hline$<5$ & 698 & 46.0 & 2.38 & $1.92-2.96$ \\
\hline \multicolumn{5}{|c|}{ Age started smoking (years) } \\
\hline$\leqslant 15$ & 3225 & 21.1 & 1.00 & Referent \\
\hline $16-19$ & 6606 & 23.1 & 1.03 & $0.92-1.16$ \\
\hline$\geqslant 20$ & 3584 & 28.1 & 1.16 & $1.01-1.32$ \\
\hline \multicolumn{5}{|c|}{ Time to first cigarette (minutes) } \\
\hline$<10$ & 4329 & 17.9 & 1.00 & Referent \\
\hline $10-30$ & 3960 & 21.1 & 1.18 & $1.05-1.33$ \\
\hline $31-60$ & 2431 & 26.2 & 1.41 & $1.23-1.62$ \\
\hline$>61$ & 2646 & 35.9 & 1.84 & $1.59-2.14$ \\
\hline \multicolumn{5}{|c|}{ Use non-cigarette product } \\
\hline No & 13003 & 24.0 & 1.00 & Referent \\
\hline Yes & 408 & 24.3 & 0.86 & $0.66-1.12$ \\
\hline \multicolumn{5}{|l|}{ Type of cigarette } \\
\hline Premium & 12078 & 24.4 & 1.00 & Referent \\
\hline Discount & 608 & 18.8 & 0.85 & $0.68-1.06$ \\
\hline Generic & 173 & 15.0 & 0.64 & $0.41-0.99$ \\
\hline \multicolumn{5}{|l|}{ Quit attempts } \\
\hline 0 & 8235 & 22.6 & 1.00 & Referent \\
\hline 1 & 2427 & 24.4 & 1.07 & $0.95-1.21$ \\
\hline$\geqslant 2$ & 2717 & 27.7 & 1.14 & $1.01-1.29$ \\
\hline \multicolumn{5}{|l|}{ Desire to quit } \\
\hline Not at all & 2200 & 22.2 & 1.00 & Referent \\
\hline A little & 2116 & 22.9 & 1.20 & $1.02-1.40$ \\
\hline Somewhat & 4216 & 22.9 & 1.13 & $0.98-1.31$ \\
\hline A lot & 4882 & 26.0 & 1.24 & $1.07-1.44$ \\
\hline \multicolumn{5}{|c|}{ Number of other household smokers } \\
\hline 0 & 7206 & 25.5 & 1.00 & Referent \\
\hline$\geqslant 1$ & 6209 & 22.1 & 0.87 & $0.80-0.95$ \\
\hline
\end{tabular}

*Adjusted for COMMIT intervention status.

$\mathrm{CI}=$ confidence intervals. 


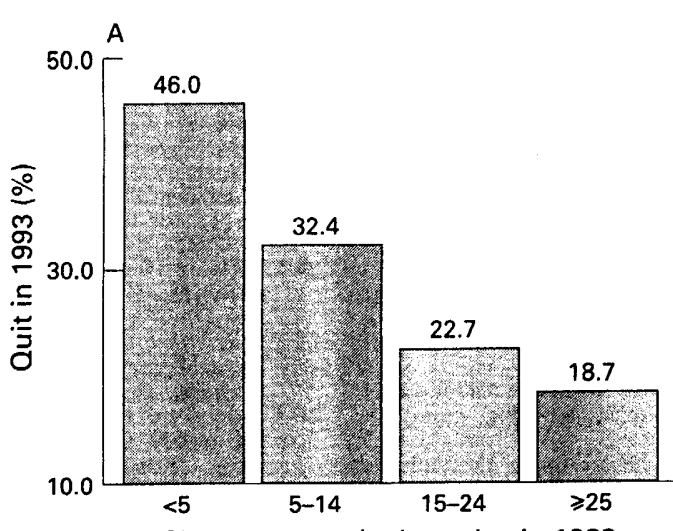

Cigarettes smoked per day in 1988

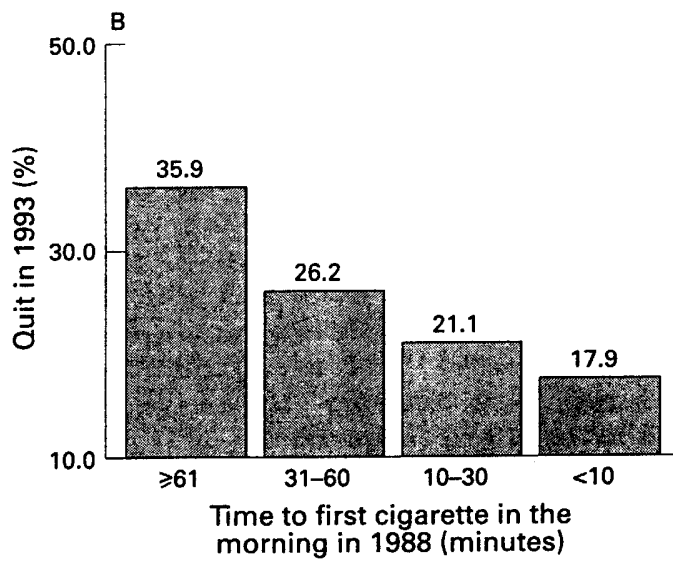

Figure 2 Relationship between measures of strength of nicotine dependence as measured in 1988 (amount smoked and time to first cigarette in the morning) and smoking cessation in 1993.

of nicotine dependence (amount smoked daily, time to first cigarette of the day).

The criteria used to define whether or not a person is addicted to a substance vary, but common to most definitions is the concept of compulsive use, even when faced with knowledge that the substance is harmful. ${ }^{6}$ The results of this study support the idea that a large percentage of adult smokers are addicted to cigarettes. For example, a third of smokers enrolled in COMMIT in 1988 reported having made an unsuccessful attempt to stop smoking in the previous year. Between 1988 and 1993, $67 \%$ of smokers reported making at least one serious effort to stop smoking between 1988 and 1993, yet only a third of those who attempted to stop smoking were classified as not smoking in 1993. Unfortunately, information about reasons for relapsing was not collected. Most smokers believe that smoking is harmful and that quitting smoking would improve their health. ${ }^{24}$ Among smokers who reported making a quit attempt, nearly all mentioned health concerns as an important factor motivating their decision to quit. This result is similar to findings presented by Gilpin et al who found that concern about their health was the most important reason smokers gave for stopping smoking. ${ }^{25}$ In 1988, two-thirds of smokers expressed either a strong or moderate desire to stop smoking, yet only $24 \%$ were not smoking when re-interviewed in 1993. Taken together, these results indicate that most adult smokers are motivated to stop smoking, but are unable to do so easily, especially those who smoke more frequently.

On a practical level, the findings from this research have both public policy and treatment implications. From a public policy perspective, our data support the view that for many smokers, smoking is not a volitional behaviour, but an addiction. ${ }^{26}$ Nicotine is believed to be the chemical in tobacco smoke which explains why people continue to use tobacco products. "The concept of smoking as an addiction offers a number of interesting, although little used, policy options including: (a) regulation of nicotine-containing cigarettes ${ }^{20.29}$; (b) the use of cigarette taxes to fund low-cost or free smoking cessation treatment programmes for smokers $^{30}$; (c) tort damage claims by smokers against cigarette manufacturers ${ }^{31}$; and (d) policies protecting smokers from discrimination in employment. ${ }^{31}$

From a treatment perspective, the findings from this study highlight the importance of helping smokers, especially heavier smokers, overcome their need for nicotine. The means to achieve this therapeutic goal could take many forms including, but not limited to, the use of nicotine replacement products, gradual reduction of the number of cigarettes smoked daily, and having smokers switch to cigarettes with less nicotine. Recent practice guidelines on smoking cessation issued by the Agency for Health Care Policy and Research emphasised the need to make support services more accessible to smokers. ${ }^{32}$ Heavy smokers are more likely to seek out assistance in quitting smoking, and evidence shows that a dose-response relation exists between the intensity and duration of treatment and its effectiveness. ${ }^{32}{ }^{33}$ Unfortunately, the reality in most healthcare and other settings today is that providers are unable to adequately address the needs of smokers who are highly dependent on nicotine.

Support for this research has been provided by the National Cancer Institute and the Robert Wood Johnson Foundation. We are indebted to our colleagues at the 11 COMMrT research sites, the COMMIT coordinating center, Information Managewho planned and coordinated the massive data collection who planned and coordinated

1 US Department of Health and Human Services. Reducing the health consequences of smoking: 25 years of progress. $A$ report of the Surgeon General, 1989. Rockville, Maryland:
Public Health Service, Centers for Disease Control, Office Public Health Service, Centers for Disease Control, Office (CDC) 89-8411.)

2 American Medical Association. 1993 AMA policy compendium. Chicago, Illinois: Ameican Medical Association, 1993:35.

3 American Psychiatric Association. Diagnostic and statistical manual of mental disorders: $D S M-I V$, 4th ed. Washington, DC: American Psychiatric Association, 1994.

4 World Health Organisation. International statistical classification of diseases and related health problems, 10 th revision. Vol 1. Geneva, Switzerland: World Health Organisation, 1993.

5 The Royal Society of Canada. Tobacco, nicotine and addiction. Ottawa, Ontario: Health Protection Branch, Health and Ottawa, Ontario: Health Protection

6 US Department of Health and Human Services. The health Separtment of Health and Human Services. The health consequences of smoking: nicotine addiction. A report of the
Surgeon General, 1988. Rockville, Maryland: Public Health Surgeon General, 1988. Rockville, Maryland: Public Health Service, Centers for Disease Control, Otfice on Smoking
and Health, 1988. (DHHS Publication No (CDC) and Heal

7 Thomas RM, Larsen MD. Smoking prevalence, beliefs, and activities by gender and other demographic indicators. Princeton, New Jersey: The Gallup Organization, 1993.

8 US Centers for Disease Control. Smoking cessation during the previous year among adults-United States. $M M W R$ 1993;42:504-7. 
9 Hymowitz N, Sexton M, Ockene J, Grandits G, for the MRFIT Research Group. Baseline factors associated with MRFIT Research Group. Baseline factors associated with 601 .

10 Killen JD, Fortmann SP, Kraemer HC, Varady A, Newman B. Who will relapse? Symptoms of nicotine dependence predict long-term relapse after smoking cessation. $f$ Consult Clin Psychol 1992;60:797-801.

11 Fagerstron KO. Measuring degree of physical dependence to tobacco smoking with reference to individualization of treatment. Addict Behav 1978;3:235-41.

12 Venters MH, Kottke TE, Solberg LI, Brekke ML, Rooney B. Dependency, social factors, and the smoking cessation B. Dependency, social factors, and the smoking cessation process: the doct

13 Farkas AJ, Pierce JP, Zhu SH, it al. Addiction versus stages of change models in predicting smoking cessation. Addiction 1996;91:1271-80.

14 Fisher EB Jr, Lichtenstein E, Haire-Joshu D. Multiple determinants of tobacco use and cessation. In: Orleans $\mathrm{CT}$, Slade J, eds. Nicotine addiction: principles and management. New York: Oxford University Press, 1993:59-88

15 Berman OB, Gutz ER. Women and smoking: current trend and issues for the 1990's. F Substance Abuse 1991;3:221-8.

16 Royce JM, Hymowitz N, Corbett K, Hartwell TD, Orland MA for the COMMIT Research Group. Smoking cessation factors among African Americans and Whites. Am $\mathcal{F}$ Public Health 1993;83:220-6.

17 COMMIT Research Group. Community Intervention Trial for Smoking Cessation (COMMIT): summary of design and intervention. 7 Natl Cancer Inst 1991;83:1620-8.

18 COMMIT Research Group. Community Intervention Trial for Smoking Cessation (COMMIT). I. Cohort results for Smoking Cessation (COMMIT). I. Cohort results from a four-year comm

19 COMMIT Research Group. Community Intervention Trial for Smoking Cessation (COMMIT). II. Changes in adult for Smoking Cessation (COMA Am $\mathcal{f}$ Public Health 1995 85:193-200.

20 US National Center for Health Statistics. Current estimates from the Health Interview Survey. Series 10, No 166. Hyattsville, Maryland: Department of Health, Education and Welfare, 1987.
21 US Centers for Disease Control. Tobacco use in 1986: methods and basic tabulations from Adult Use of Tobacco Survev Rockville, Maryland: Department of Health and Human Services, 1989

22 Prochaska JO, DiClemente CC. Stages and processes of self-change in smoking: towards and integrative model of self-change in smoking: towards and integra
change. F Consult Clin Psychol 1983;5:390-5.

23 Lichtenstein E, Glasgow RE. Smoking cessation: what have we learned over the past decade? $\mathcal{f}$ Consult Clin Psychol 1992;60:1-10.

24 US Centers for Disease Control. Smokers' beliefs about the health benefits of smoking cessation-20 U.S. communities. MMWR 1990;39:653-6.

25 Gilpin E, Pierce JP, Goodman J, et al. Reasons smokers give for stopping smoking: do they relate to success in for stopping smoking: do they relate

26 US Food and Drug Administration. Notice; analysis regarding agency jurisdiction: analysis regarding the Food and ing agency jurisdiction: analysis regarding the Food and Drug Administration's jurisdiction over nicotineFederal Register 1995;60:41453-786.

27 US Food and Drug Administration. Proposed rule: regulations restricting the sale and distribution of cigarettes and smokeless tobacco products to protect children and adolescents. Federal Register 1995;60:41314-75.

28 Benowitz NL, Henningfield JE. Establishing a nicotin threshold for addiction. $N$ Engl $f$ Med 1994;331:123-5.

29 Henningfield JE. Introduction to tobacco harm reduction as a complementary strategy to smoking cessation. Tobacco Control 1995;4(suppl 2):S25-32.

30 Warner KE, Slade J, Sweanor DT. The emerging market for long-term nicotine maintenance. JAMA 1997;278:108792.

31 Rabin RL, Sugarman SD. Overview. In: Rabin RL, Sugarman SD, eds. Smoking policy: law, politics and culture. New York: Oxford University Press, 1993:9-13.

32 Fiore MC, Bailey WC, Cohen SJ, et al. Smoking cessation. Clinical Practice Guideline No 18. Rockville, Maryland: Clinical Practice Guideline No 18. Rockville, Maryland: US Department of Health and Human Services, Public Health Service, Agency for Health Care Policy and (AHCPR Publication No 96-0692.)

33 Fiore MC, Novotny TE, Pierce JP, et al. Methods used to quit smoking in the United States. help? ҰAMA 1990;263:2760-5. 